\title{
Mechanisms of Action and Dose-Response Relationships Governing Biological Control of Fusarium Wilt of Tomato by Nonpathogenic Fusarium spp.
}

\author{
Robert P. Larkin and Deborah R. Fravel
}

USDA-ARS, Biocontrol of Plant Diseases Laboratory, Beltsville, MD 20705.

Current address of R. P. Larkin: USDA, ARS, New England Plant, Soil, and Water Lab, University of Maine, Orono 04469.

Accepted for publication 3 August 1999.

\begin{abstract}
Larkin, R. P., and Fravel, D. R. 1999. Mechanisms of action and doseresponse relationships governing biological control of Fusarium wilt of tomato by nonpathogenic Fusarium spp. Phytopathology 89:1152-1161.

Three isolates of nonpathogenic Fusarium spp. (CS-1, CS-20, and Fo47), previously shown to reduce the incidence of Fusarium wilt diseases of multiple crops, were evaluated to determine their mechanisms of action and antagonist-pathogen inoculum density relationships. Competition for nutrients, as represented by a reduction in pathogen saprophytic growth in the presence of the biocontrol isolates, was observed to be an important mechanism of action for isolate Fo47, but not for isolates CS-1 and CS-20. All three biocontrol isolates demonstrated some degree of induced systemic resistance in tomato (Lycopersicon esculentum) and watermelon (Citrullus lanatus) plants, as determined by split-root tests, but varied in their relative abilities to reduce disease. Isolate CS-20 provided the most effective control (39 to 53\% disease reduction), while Fo47 provided the least effective control (23 to $25 \%$ reduction) in split-root tests. Dose-response relationships also differed considerably among the three biocontrol isolates, with CS-20 significantly reducing disease incidence at an-

tagonist doses as low as 100 chlamydospores per $\mathrm{g}$ of soil (cgs) and at pathogen densities up to $10^{5} \mathrm{cgs}$. Isolate CS- 1 also was generally effective at antagonist densities of 100 to 5,000 cgs, but only when pathogen densities were below $10^{4} \mathrm{cgs}$. Isolate Fo47 was effective only at antagonist densities of $10^{4}$ to $10^{5} \mathrm{cgs}$, regardless of pathogen density. Epidemiological dose-response models (described by linear, negative exponential, hyperbolic saturation [HS], and logistic [LG] functions) fit to the observed data were used to quantify differences among the biocontrol isolates and establish biocontrol characteristics. Each isolate required a different model to best describe its dose-response characteristics, with the HS/HS, LG/HS, and LG/LG models (pathogen/biocontrol components) providing the best fit for isolates CS-1, CS-20, and Fo47, respectively. Model parameters defining effective biocontrol dose $\left(\mathrm{ED}_{50}\right)$ indicated an $\mathrm{ED}_{50}$ of 2.6, 36.3, and $2.1 \times 10^{6} \mathrm{cgs}$ and estimates of biocontrol efficiency of $0.229,0.539$, and 0.774 for isolates CS-1, CS-20, and Fo47, respectively. Differences in dose-response relationships among the biocontrol isolates were attributed to differences in their mechanisms of action, with CS-20 and CS-1 functioning primarily by induced resistance and Fo47 functioning primarily by competition for nutrients.
\end{abstract}

Biological control of Fusarium wilt diseases, caused by pathogenic formae speciales of Fusarium oxysporum Schlechtend.:Fr., has shown potential as an alternative disease management strategy $(4,7)$. Antagonist organisms, including nonpathogenic Fusarium spp., have successfully reduced the incidence of Fusarium wilt in numerous crops in greenhouse and field trials $(2,3,7,17,19,28)$.

Previously, we demonstrated the efficacy of several strains of nonpathogenic Fusarium spp. isolated from a wilt-suppressive soil in controlling Fusarium wilt of tomato and other vegetable crops in greenhouse tests (17). Selected isolates were equally effective at reducing Fusarium wilt of tomato, watermelon, and muskmelon in repeated tests, with reductions in disease incidence of 60 to $80 \%$ relative to the pathogen-infested controls (17).

However, for biological control to be implemented commercially on a practical level, it is necessary to more fully understand the ecology of these biocontrol organisms and their interactions with the pathogen, host plant, and surrounding soil and rhizosphere microbial communities $(5,10,20)$. Ideally, the antagonists must be ecologically fit to survive and function within the particular conditions of the ecosystem. Moreover, the antagonists must be present at adequate population levels and be capable of effectively interacting

Corresponding author: R. P. Larkin; E-mail address: larkin@maine.edu

Publication no. P-1999-1005-01R

This article is in the public domain and not copyrightable. It may be freely reprinted with customary crediting of the source. The American Phytopathological Society, 1999. with the pathogen or host plant to provide acceptable disease control. Understanding the mechanism(s) of action involved in biocontrol processes is of primary importance in establishing these characteristics and can provide much insight into where and when the interaction occurs and how the pathogen will be affected. The mechanism of action also will determine, to a large degree, how the antagonist will need to be implemented and managed, as well as suggest potential strategies that may improve control. Knowledge of antagonist-pathogen inoculum density relationships can determine the population levels of the antagonists that are required to achieve adequate disease control, as well as the pathogen population levels at which the antagonists will or will not be effective.

The two primary mechanisms of action associated with nonpathogenic isolates of Fusarium spp. are competition and induced systemic resistance (ISR). Competition can be further categorized into saprophytic competition for nutrients in the soil and rhizosphere $(2,6,22,24)$ and parasitic competition for infection sites on the root (30). ISR refers to the systemic induction of defense responses within the plant caused by some biotic or abiotic inducing agent (14). In this case, ISR involves the colonization of roots by certain organisms, resulting in some level of systemic resistance to the pathogen. This phenomenon has been observed with other F. oxysporum strains $(9,15,24,25,27)$, as well as with certain other fungi and bacteria $(13,21,23,35)$. Nonpathogenic $F$. oxysporum isolate Fo47, which was recovered from a Fusarium wilt-suppressive soil in France, has been extensively studied as a potential biocontrol agent for the control of Fusarium wilt diseases of several vegetable and flower crops (2-4). The mechanism of action of this isolate involves sap- 
rophytic competition for nutrients $(3,6,22)$. Recently, this isolate was also shown to induce resistance to Fusarium wilt of tomato $(9,16)$. However, the extent of the role of ISR in biological control by Fo47 has not been elucidated.

In recent years, epidemiological dose-response models have been used to describe and characterize the effects of biocontrol agents on disease reduction and development $(8,12,26,29,31)$. In most of these models, the degree of disease control obtained with a biocontrol agent depends on the density of the biocontrol agent, the density of the pathogen, the efficiency of the biocontrol agent in suppressing the pathogen, and the proportion of the pathogen population that is potentially affected by the agent $(12,26,31)$. Such models can be useful for comparing different biocontrol agents and systems, may help in understanding the factors affecting biocontrol interactions, and may be useful in predicting biocontrol efficacy under varying conditions.

The objectives of this research were to determine the primary mechanisms of action and the antagonist-pathogen inoculum density relationships governing biological control by three isolates of Fusarium spp. (CS-1, CS-20, and Fo47) that have been previously shown to have potential as biocontrol agents for the control of Fusarium wilt diseases. In addition, epidemiological dose-response models were used to describe and characterize differences among the isolates. A preliminary report of portions of this work has been published (16).

\section{MATERIALS AND METHODS}

Fungal isolates and inoculum production. Antagonistic and pathogenic isolates of Fusarium spp. used in this study are listed in Table 1. Biocontrol isolates CS-1 and CS-20 were isolated from watermelon plants grown in a wilt-suppressive soil in Florida (18, 19), whereas Fo47 was isolated from a wilt-suppressive soil in France $(2,3)$. Isolate Fo47 has been developed as a commercial biocontrol agent (2-4) and was included in these tests primarily for comparison with the potential biocontrol isolates CS-1 and CS-20. Isolates of $F$. oxysporum f. sp. lycopersici, F. oxysporum f. sp. basilici, and F. oxysporum f. sp. niveum, Fusarium wilt pathogens on tomato (Lycopersicon esculentum Mill.), basil (Ocimum basilicum L.), and watermelon (Citrullis lanatus (Thunb.) Matsum. \& Nakai), respectively, were used in various tests as described. Stock cultures of all Fusarium strains were stored in soil, on filter paper, or on dried toothpicks. Toothpick storage was obtained by placing autoclaved wooden toothpicks on the surface of potato dextrose agar (PDA) plates, inoculating the plate with fungi, and incubating at $25^{\circ} \mathrm{C}$ for 7 days or until toothpicks were covered with mycelium. Toothpicks were then aseptically removed, allowed to dry overnight, and transferred to screw-cap vials for storage at room temperature.

Inoculum was produced in an aqueous suspension of $1 \%(\mathrm{wt} / \mathrm{vol})$ ground soybean hull fiber (Dietfiber soy fiber; Lauhoff Grain Co., Danville, IL) (11). Flasks containing $100 \mathrm{ml}$ of the autoclaved fiber suspension were inoculated with agar blocks from 7-day-old PDA culture plates. Liquid cultures were grown for 10 to 14 days on a rotary shaker at $135 \mathrm{rpm}$ at $25^{\circ} \mathrm{C}$, blended, and propagule counts determined with a hemacytometer. For most experiments, inoculum concentration was adjusted to $10^{6}$ propagules per $\mathrm{ml}$. Inoculum consisted of a mixture of conidia and chlamydospores. For experiments that used only chlamydospore inoculum, stock soil cultures were established by adding $100 \mathrm{ml}$ of a homogenized 10-day-old soy fiber culture to $1 \mathrm{~kg}$ of autoclaved field soil (Galestown gravelly loamy sand), mixed thoroughly, and allowed to slowly dry. After 4 weeks, all propagules had converted to chlamydospores, and propagule counts were determined by soil dilution plating on Komada's medium (KM) (14). The appropriate amount of this stock soil was then added to field soil to produce the chlamydospore inoculum density level required for each treatment.

Disease assays. For most disease assays, tomato seeds of the cv. Bonny Best (Totally Tomatoes, Augusta, GA) were planted in soilless potting mix (Redi-Earth; Scotts-Sierra Inc., Marysville, $\mathrm{OH}$ ) and grown in seedling plug trays $(3.4 \times 3.4 \times 5$-cm plug size, 98 plugs per tray). The potting mix was either infested with the biocontrol isolate to be tested or left untreated. Five milliliters of a liquid culture suspension of $10^{6}$ propagules per $\mathrm{ml}$ of the biocontrol isolate was added to each plug cell at the time of planting. Five tomato seeds were planted in each cell of the plug tray, watered as needed, and maintained in the greenhouse at 20 to $28^{\circ} \mathrm{C}$. After 2 weeks, plugs containing the tomato plants were transplanted into $10-\mathrm{cm}-$ diameter pots containing nonsterile field soil (Galestown gravelly loamy sand) infested with the Fusarium wilt pathogen. Pathogen inoculum consisted of $F$. oxysporum f. sp. lycopersici grown in a liquid soy culture as described previously. Final pathogen inoculum density in field soil was $10^{4}$ propagules per $g$ of soil.

Each treatment consisted of five replicate pots of five plants per pot arranged in a randomized complete block experimental design. Disease was monitored for 4 to 6 weeks and assayed as the total percentage of seedlings showing any symptoms of Fusarium wilt (yellowing, dropping of leaves, vascular discoloration, etc.). Stem sections of wilted seedlings were surface-disinfested in $0.5 \%$ sodium hypochlorite and plated on KM to confirm the presence of the wilt pathogen.

Pathogen chlamydospore germination assay. The effect of the biocontrol isolates on chlamydospore germination of the pathogen in soil at increasing glucose concentrations was assessed using a buried membrane filter technique as described previously (18). Glucose solutions were added to soil at concentrations ranging from 0 to $0.4 \mathrm{mg} / \mathrm{g}$ of soil to stimulate chlamydospore germination and to simulate the nutrients provided by root exudates. Chlamydospores were produced in liquid culture as described above. Chlamydospore suspensions were adjusted to $3 \times 10^{4}$ chlamydospores per $\mathrm{ml}$, and $1 \mathrm{ml}$ of this suspension was deposited by vacuum filtration on a $25-\mathrm{mm}$ Millipore membrane filter (type HA, $0.45 \mu \mathrm{m}$ ) with a grid on one side. The filters were buried in $100 \mathrm{~g}$ of soil that was infested with $10^{3}$ chlamydospores per $\mathrm{g}$ of soil (cgs) of the appropriate biocontrol isolate treatment and moistened to a matric potential of $-0.1 \mathrm{MPa}$. After incubation in a moist chamber for $24 \mathrm{~h}$ at $25^{\circ} \mathrm{C}$, the filters were removed, rinsed, and stained with trypan blue-lactophenol as described previously (18). Filters were examined at $\times 200$ magnification and the percentage of chlamydospore germination and the average length of the germ tube calculated. Tests were conducted using two different Fusarium wilt

TABLE 1. Description, characteristics, and sources of Fusarium spp. biocontrol and pathogen isolates used in this study

\begin{tabular}{|c|c|c|c|}
\hline Isolate & Organism & Characteristics & Source \\
\hline CS-1 & F. solani & Nonpathogen, biocontrol agent & FWS $^{a}$ soil, Florida (19) \\
\hline CS-20 & F. oxysporum & Nonpathogen, biocontrol agent & FWS soil, Florida (19) \\
\hline Fo47 & F. oxysporum & Nonpathogen, biocontrol agent & FWS soil, France $(2,3)$ \\
\hline IA-7 & F. oxysporum f. sp. lycopersici & Pathogen of tomato & R. Schneider ${ }^{b}$ \\
\hline MD-1 & F. oxysporum f. sp. basilici & Pathogen of basil & E. Dutkey ${ }^{c}$ \\
\hline CS93-8 & $F$. oxysporum f. sp. niveum & Pathogen of watermelon & D. L. Hopkins ${ }^{d}$ \\
\hline
\end{tabular}

${ }^{a}$ FWS = Fusarium wilt-suppressive soil.

b Louisiana State University, Baton Rouge.

c University of Maryland, College Park.

d University of Florida, Central Florida Research and Education Center, Leesburg. 
pathogens, the tomato pathogen and the basil pathogen. Six replications of at least 100 chlamydospores per replicate were used in a completely randomized design, and the experiment was repeated twice for each pathogen isolate.

ISR assay. A split-root technique, in which young root systems were divided into two halves and placed in separate pots, was used to spatially separate the biocontrol agent from the pathogen as described previously (19). One half of the root system was exposed to the treatment, either untreated soil or soil with a biocontrol isolate added, and the other half of the root system was exposed to the pathogen. Five milliliters of a liquid culture suspension of $10^{6}$ propagules per $\mathrm{ml}$ of each biocontrol isolate was added to the appropriate treatment pot at the time of planting the split-root seedling. Pathogen inoculum (same dosage as biocontrol isolate) was added to the pathogen pot 3 days later. Experiments were randomized complete block designs consisting of 20 to 24 plants for each treatment combination (four replicate blocks of five to six plants each). Additional individual and split-root control plants were planted in the two-pot system to sample and test for cross-contamination by either the antagonist or pathogen between the pots. Plants were watered as needed and grown in the greenhouse for 5 weeks at 20 to $28^{\circ} \mathrm{C}$. Stem sections of wilted plants were surface-disinfested and plated on KM. Stems of all plants were plated at the conclusion of the experiment. Assays were done on both watermelon and tomato plants using the appropriate wilt pathogen. This experiment was conducted twice on both hosts.

TABLE 2. Pathogen-biocontrol dose-response models expressing the proportion of disease incidence $(Y)$ as a function of the inoculum dose of the pathogen $(x)$ and the biocontrol agent $(z)$

\begin{tabular}{|c|c|c|c|c|}
\hline \multirow[b]{2}{*}{ Model $^{\mathrm{a}}$} & \multirow[b]{2}{*}{ Equation } & \multicolumn{3}{|c|}{$\begin{array}{c}\text { Model } \\
\text { parameters }^{\mathrm{b}}\end{array}$} \\
\hline & & A & $\mathrm{R}$ & $\mathrm{ED}_{5}$ \\
\hline $\begin{array}{l}\text { Pathogen component } \\
\text { Linear }\end{array}$ & $Y=a+b x B$ & $a$ & $b$ & $\cdots$ \\
\hline Negative exponential & $Y=L[1-\exp (-k x B)]$ & $L$ & $k$ & .. \\
\hline Hyperbolic saturation & $Y=Y_{m}\left(\frac{x B}{x B+K_{x}}\right)$ & $Y_{m}$ & $\ldots$ & $K_{x}$ \\
\hline Logistic & $Y=\frac{1}{\left\{1+\exp \left[-k_{1}\left(x B-p_{1}\right)\right]\right\}}$ & $\ldots$ & $k_{1}$ & $p_{1}$ \\
\hline \multicolumn{5}{|l|}{ Biocontrol component } \\
\hline Linear & $B=1-\left(x_{i} / x\right)=1-(c-d z)$ & $c$ & $d$ & $\cdots$ \\
\hline Negative exponential & $B=1-\left(x_{i} / x\right)=1-\left\{A\left[1-\exp \left(-c_{n} z\right)\right]\right\}$ & A & $c_{n}$ & $\ldots$ \\
\hline Hyperbolic saturation & $B=1-\left(x_{i} / x\right)=1-\left[I_{m}\left(\frac{z}{z+K_{z}}\right)\right]$ & $I_{m}$ & $\ldots$ & $K_{z}$ \\
\hline Logistic & $B=1-\left(x_{i} / x\right)=1-\left\{\frac{1}{1+\exp \left[-K_{1}\left(z-P_{1}\right)\right]}\right.$ & $\ldots$ & $K_{1}$ & $P_{1}$ \\
\hline
\end{tabular}

${ }^{a}$ Each model consists of a pathogen component and a biocontrol component, each of which uses two parameters to relate disease incidence to inoculum dose. The biocontrol component $\left(x_{i} / x\right)$ expresses the proportion of the pathogen rendered ineffective by the biocontrol agent. For inclusion into the pathogen model, $1-\left(x_{i} / x\right)$ or $B$ is multiplied by the pathogen inoculum dose $(x)$, which represents the proportion of remaining effective pathogen inoculum not rendered ineffective by the biocontrol agent. Thus, when no biocontrol agent is present, $z=0, x_{i} / x=0$, and $B=1$, resulting in no reduction in pathogen effectiveness.

${ }^{\mathrm{b}}$ Model equations and explanations of components are derived from references $(9,13,31,36)$. Each model parameter defines either an asymptote (A), a rate of change $(\mathrm{R})$, or an $\mathrm{ED}_{50}$. An asymptote represents the maximum potential for disease or disease suppression. Rate parameters define how rapidly disease changes with respect to increasing inoculum. The $\mathrm{ED}_{50}$ defines the dose at which disease or biological control is half the maximum, either $50 \%$ disease (pathogen component) or $50 \%$ of the maximum reduction of disease (biocontrol component).
Antagonist-pathogen inoculum density relationships. Chlamydospore inoculum for the pathogen and all three biocontrol isolates was prepared in soil cultures as described previously. Inoculum of the antagonists was incorporated into the potting mix prior to planting at five different antagonist densities: 0, 100, 500, 1,000, and 5,000 cgs. Pathogen inoculum was added to nonsterile field soil at the appropriate amounts to produce five or six pathogen densities $(0,100,500,2,500$, and 12,500 cgs were used in both tests, and 1,000 cgs was used only in the first test). Five tomato seeds were planted per plug, and seedlings were grown for 2 weeks and then transplanted into the pathogen-infested field soil as described previously. There were five replicate pots of four to five plants per pot for each inoculum density combination arranged in a randomized complete block design. This experiment was conducted twice. A follow-up experiment also was conducted to determine the efficacy of CS-1 and CS-20 at high pathogen densities. In this additional test, antagonist density was held constant at $10^{3} \mathrm{cgs}$, while pathogen density was tested at $2.5 \times 10^{3}, 10^{4}, 2.5 \times 10^{4}$, and $10^{5} \mathrm{cgs}$. All other procedures were as described previously for inoculum density and disease assay tests.

Modeling of dose-response relationships. The pathogen and biocontrol models generated were based on three different nonlinear functions: the modified negative exponential (NE), hyperbolic saturation (HS), and logistic (LG) functions. In addition, a linear (LN) function also was used for comparison with the nonlinear models. These models were used as proposed, described, and evaluated previously by Johnson (12), Montesinos and Bonaterra (26), and Smith et al. (31). Model equations are shown in Table 2. Each

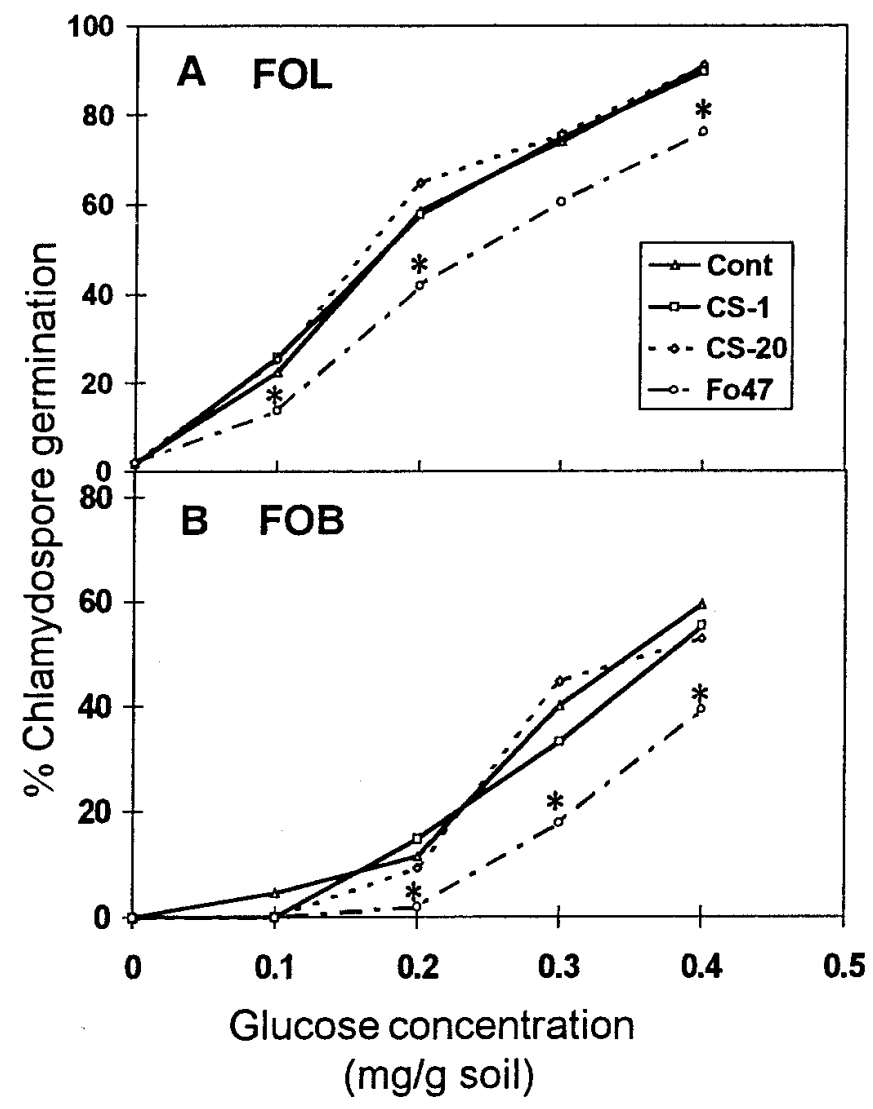

Fig. 1. Chlamydospore germination of two different Fusarium wilt pathogens, A, Fusarium oxysporum f. sp. lycopersici (FOL) and B, F. oxysporum f. sp. basilici (FOB), in soil as affected by the presence of three different biocontrol isolates (CS-1, CS-20, and Fo47) and increasing glucose concentrations. Asterisks indicate a significant reduction in chlamydospore germination due to isolate Fo47 relative to the pathogen control treatment for each glucose concentration according to Fisher's least significant difference test. The other two biocontrol isolates gave no significant effect. Data represent combined results from two similar experiments. 
model consists of two components, the pathogen component and the biocontrol component. The pathogen component relates disease incidence to pathogen inoculum dose using two parameters. The biocontrol component relates the proportion of pathogen inoculum functionally rendered ineffective $\left(x_{i} / x\right)$ to the biocontrol agent inoculum dose $(z)$, also using two parameters. The complete model consists of the pathogen component model multiplied by one of the biocontrol functions (termed $B$ or $1-\left[x_{i} / x\right]$ ). The parameters describe either an asymptote (NE and HS models), effective dose $\left(\mathrm{ED}_{50}\right)$ (HS and LG models), or rate of disease change (LN, NE, and LG models). Asymptote parameters correspond to the maximum potential for disease or disease suppression. $\mathrm{ED}_{50}$ parameters define the dose at which disease or biological control is half the maximum. Rate parameters determine how rapidly disease changes with respect to increasing inoculum dose of either the pathogen or biocontrol isolate. Thus, the combined pathogen-biocontrol models have four parameters relating disease incidence to pathogen and biocontrol inoculum dose. To reduce problems with overparameterization, the best fit for the pathogen component of the models was determined using data from the pathogen-only controls; thus, the effect of pathogen inoculum dose alone (without biocontrol agents added) was used to determine the parameters for the pathogen part of the model and fixed as constants before calculating the effect of the biocontrol agents, as recommended by Montesinos and Bonaterra (26) and Smith et al. (31). Best fit was determined for all models using the combined data from all three inoculum density tests. All combinations of pathogen and biocontrol model components were tested in the combination models. Both raw (nontransformed) and $\log _{10}$-transformed values $\left(\log _{10}[x+1]\right)$ for pathogen and biocontrol isolate inoculum density were tested in all of the models. Because these models require disease data to be expressed as a proportion between 0 and 1, percent disease incidence was converted to the proportion of disease incidence by dividing by 100 .

Statistical analyses. Statistical analyses for data from most assays, including chlamydospore germination, ISR, and inoculum density tests, were conducted using the general linear models procedures of the Statistical Analysis Systems version 6.08 (SAS Institute, Inc., Cary, NC). Experiments were analyzed using standard analysis of variance (ANOVA) with factorial treatment structure and interactions. Significance was evaluated at $P<0.05$ for all tests. Mean separation was accomplished using Fisher's protected least significant difference test. All data expressed as percentages were arcsine-transformed $\left(\sin ^{-1} \sqrt{ } x\right)$ before analysis. Inoculum density data were initially analyzed using ANOVA and orthogonal polynomial contrasts to determine significant trends among patho-

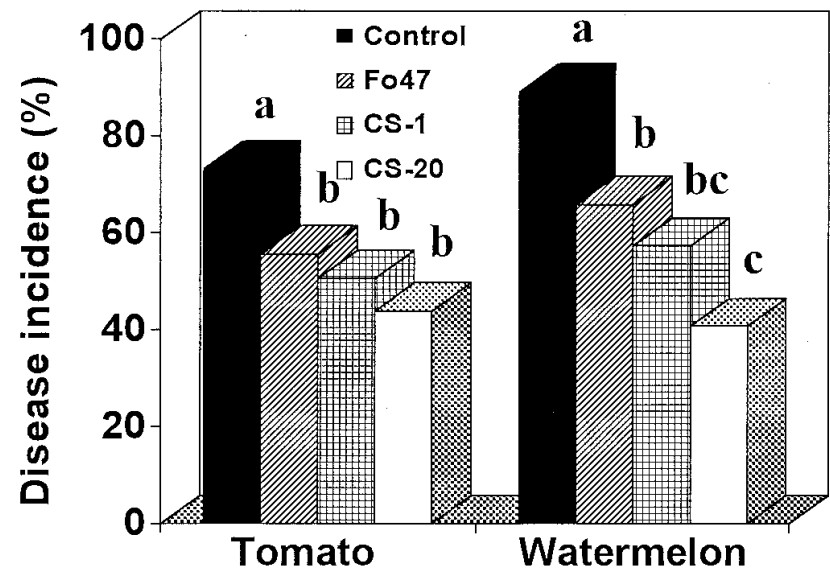

Fig. 2. Development of Fusarium wilt disease in split-root tomato and watermelon plants with one half of each root exposed to the wilt pathogen and the other half exposed to nontreated soil or biocontrol isolate treatments (CS-1, CS-20, or Fo47). Bars topped by the same letter for each host plant are not significantly different according to Fisher's protected least significant difference test $(P<0.05)$. Data represent combined results from two similar tests. gen and biocontrol isolate inoculum density relationships. Linear regression analysis of log-transformed density values was then used to quantify and distinguish these trends. Pathogen and biocontrol models were fit to the proportion of disease incidence (percent disease incidence/100) using SAS nonlinear regression procedures (Proc NLIN) with the Guass-Newton method of iteration. Evaluation of model fit was determined by comparison of the mean square error (MSE) and by comparison of model predictions versus observed values (chi-square test).

\section{RESULTS}

Mechanisms of action. Less than $2 \%$ of the chlamydospores of either pathogen isolate ( $F$. oxysporum f. sp. lycopersici or $F$. oxysporum $\mathrm{f}$. sp. basilici) germinated in field soil without the addition of glucose. Chlamydospores of both pathogen isolates germinated readily with glucose additions of 0.2 to $0.4 \mathrm{mg} / \mathrm{g}$ of soil (Fig. 1). The presence of biocontrol isolates CS-1 and CS-20 in the soil had no effect on pathogen chlamydospore germination with increasing glucose concentrations for either the tomato or basil pathogen isolates (Fig. 1). Isolate Fo47, however, significantly inhibited pathogen chlamydospore germination at glucose concentrations of $0.2 \mathrm{mg} / \mathrm{g}$ of soil and greater for both pathogen isolates (Fig. 1). In addition, germ tube growth also was significantly reduced in soil containing Fo47 compared with untreated soil (data not shown), whereas isolates CS-1 and CS-20 had no effect on germination or germ tube development in these tests. This indicated that saprophytic competition for nutrients was a mechanism of action for isolate Fo47, but that this mechanism was apparently not active or was of much lesser importance for isolates CS-1 and CS-20.

The split-root technique successfully separated the pathogen from the antagonist in soil and on the roots. Individual control plants, as well as split-root plants, were not infected with the pathogen, and there was no cross-contamination on roots between pots. In addition, antagonist strains were not isolated from stem sections of either healthy or diseased plants, indicating that these isolates did not invade the vascular tissue or move systemically within the plants. Treatments with each of the three biocontrol isolates (Fo47, CS-1, and CS-20) significantly reduced disease compared with the untreated control on both tomato and watermelon plants (Fig. 2). There was variability among the three isolates regarding the degree of disease suppression observed, however, with CS-20 generally being the most effective (39 to $53 \%$ reduction of disease incidence) and Fo47 the least effective ( 23 to $25 \%$ reduction) of the three isolates. Isolate Fo47 often resulted in marginal effects and was not always distinguishable from controls in individual experiments. Therefore, in these tests, all three isolates had some capacity to induce defense responses in both tomato and watermelon plants, but there were varying degrees of efficacy in the abilities of these isolates to suppress disease by induced resistance. Con-

TABLE 3. Overall factorial analysis of variance table for inoculum density experiment 1 , showing effects and interactions due to the factors biocontrol isolate, pathogen density, and antagonist density on development of Fusarium wilt of tomato

\begin{tabular}{lccc}
\hline & \multicolumn{3}{c}{ Analysis parameters $^{\mathrm{a}}$} \\
\cline { 2 - 4 } Source of variation & $\mathrm{df}$ & $F$ & $P$ \\
\hline Biocontrol isolate (I) & 2 & 4.3 & $0.0145^{*}$ \\
Pathogen density (P) & 4 & 51.1 & $0.0001^{* *}$ \\
Antagonist density (A) & 4 & 8.0 & $0.0001^{* *}$ \\
I*P & 7 & 3.9 & $0.0004^{* *}$ \\
I*A $^{*}$ & 8 & 1.7 & 0.095 \\
P $^{*} \mathrm{~A}$ & 16 & 0.7 & 0.810 \\
I*P*A $^{*}$ & 28 & 0.9 & 0.666 \\
\hline
\end{tabular}

a $\mathrm{df}=$ Degrees of freedom, $F=$ value of $F$ statistic, and $P=$ probability or level of significance. Probabilities of less than 0.05 and 0.001 are followed by single and double asterisks, respectively. Error $\mathrm{df}=280$, total $\mathrm{df}=349$, and mean square error $=319.7$. 
sequently, isolates CS-20 and CS-1 apparently suppress disease primarily by induced resistance, whereas Fo47 combines competition with some partial level of ISR.

Antagonist-pathogen inoculum density relationships. In general, all three main factors, biocontrol isolate, pathogen density, and antagonist density, significantly affected development of Fusarium wilt of tomato in these tests, with a significant interaction between biocontrol isolate and pathogen density (I*P) (Table 3). This interaction indicates that the level of disease control provided by the antagonists differed among the three biocontrol isolates in relation to increasing pathogen densities. Subsequent analyses conducted on data from each of the three biocontrol isolate treatments individually demonstrated significant effects due to pathogen den-
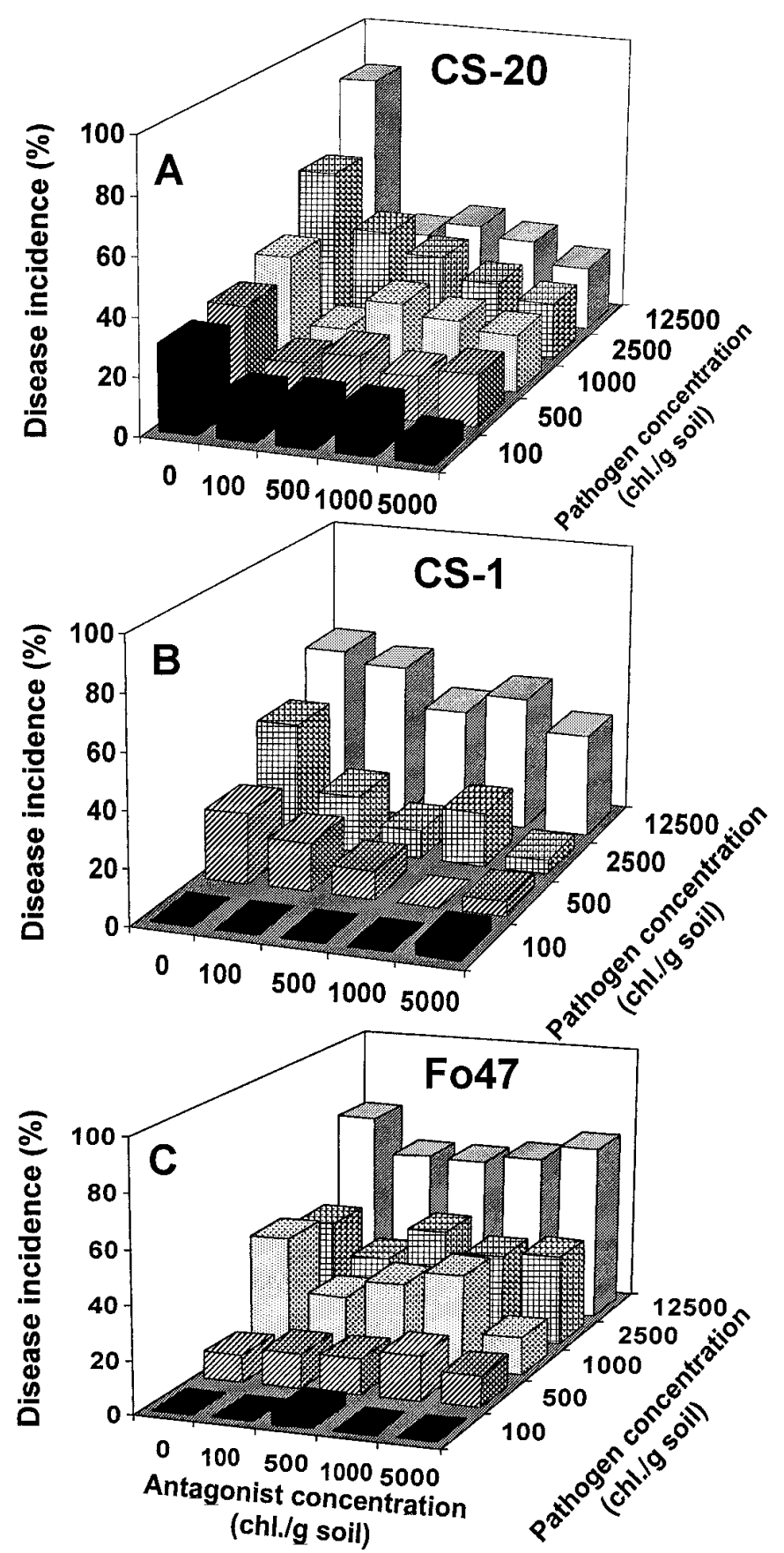

Fig. 3. Effect of varying pathogen and antagonist inoculum densities on the development of Fusarium wilt of tomato for three different biocontrol isolates, A, Fusarium oxysporum isolate CS-20; B, F. solani isolate CS-1; and C, F. oxysporum isolate Fo47. Isolate densities are expressed as chlamydospores per $\mathrm{g}$ of soil. Data represent results of a single representative test. sity for all three isolates $(P<0.0003)$ and to antagonist density for CS-20 and CS-1 $(P<0.0001$ and 0.003 , respectively), but the presence and density of isolate Fo47 (up to $5 \times 10^{3} \mathrm{cgs}$ ) did not significantly affect disease $(P=0.626)$. Significant linear trends were evident with increasing pathogen densities $(P<0.0001)$ for all three antagonist isolates and with increasing antagonist densities for CS-20 and CS-1 $(P<0.0001)$, but not for Fo47 $(P=0.324)$, according to orthogonal polynomial trend contrasts. Isolate CS-1 also demonstrated a significant quadratic trend with increasing pathogen densities $(P=0.024)$ that was not present for the other two isolates (data not shown).

When no antagonist was present (0 level), disease incidence ranged from 0 to $>80 \%$ with increasing pathogen densities in experiment 1 . When treated with biocontrol isolate CS-20 at densities as low as $100 \mathrm{cgs}$, however, reductions of disease incidence were apparent (compared with the pathogen control -0 antagonist level) at all pathogen densities, including the highest pathogen density of $1.25 \times 10^{4}$ cgs (Fig. 3). Increasing antagonist densities of CS-20 from 500 to 5,000 cgs, however, did not necessarily increase the extent of disease control observed. Control, in general, was as good at the lowest density (100 cgs) as at higher densities (500 to 5,000 cgs) with

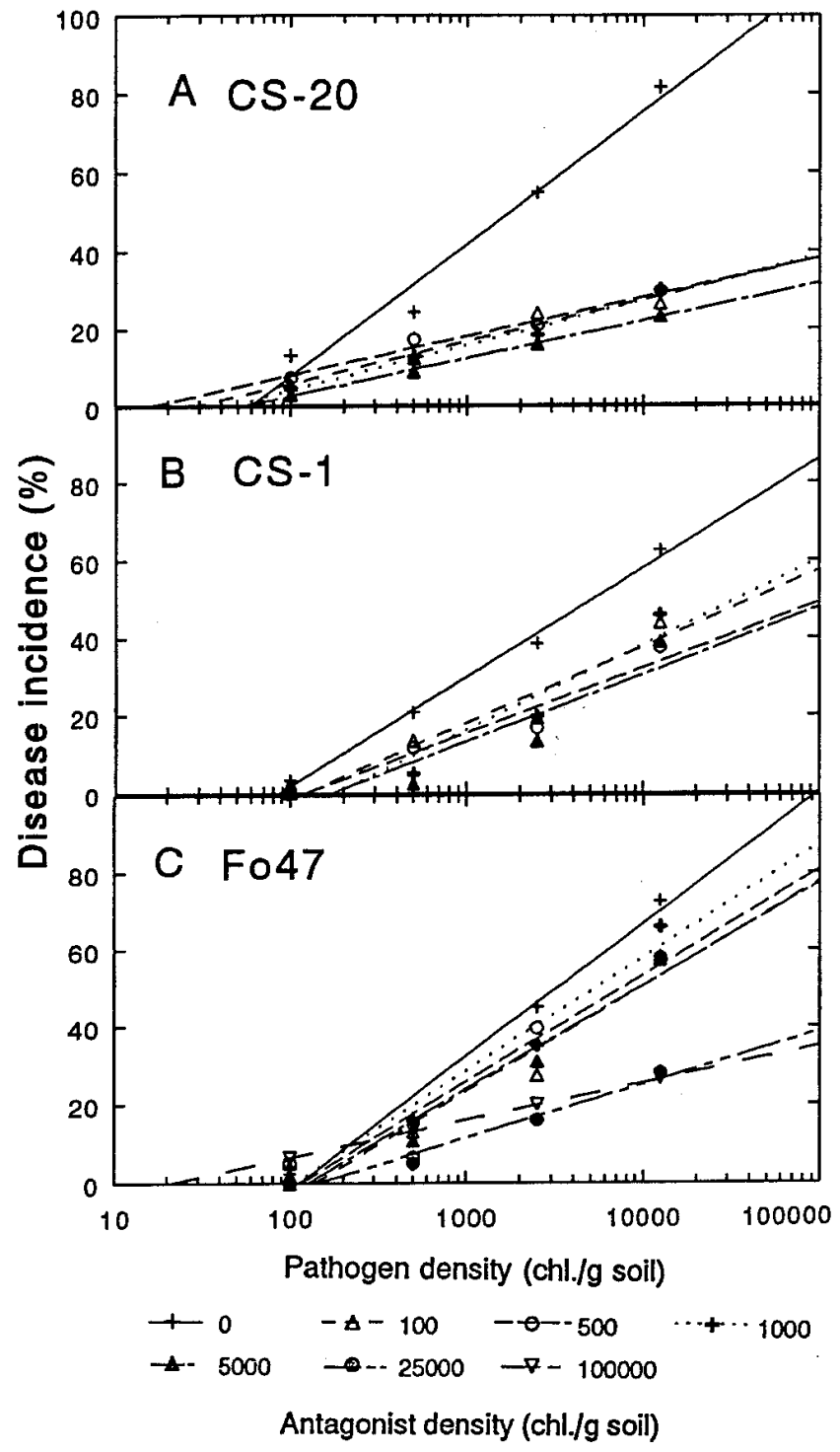

Fig. 4. Effect of varying antagonist inoculum densities on incidence of Fusarium wilt of tomato over increasing pathogen densities for three biocontrol isolates, A, Fusarium oxysporum isolate CS-20; B, F. solani isolate CS-1; and C, F. oxysporum isolate Fo47. Isolate densities are expressed as chlamydospores per $\mathrm{g}$ of soil. Data represent combined results from two similar tests. 
this biocontrol isolate. With biocontrol isolate CS-1, low to moderate antagonist densities (100 to 5,000 cgs) were generally effective at reducing disease at moderate pathogen densities, up to 2,500 cgs. However, at the highest pathogen density tested $\left(1.25 \times 10^{4} \mathrm{cgs}\right)$, there was no significant reduction of disease at any antagonist level.

For isolate Fo47, there was no significant reduction of Fusarium wilt at any of the antagonist levels tested (up to 5,000 cgs), regardless of the pathogen density. The only individual treatment in which there appeared to be any reduction of disease was when the antagonist substantially outnumbered the pathogen (e.g., antagonist $=5,000$, pathogen $=1,000$ ). Because of this observation, in the repeat of this test, the two lowest antagonist densities (100 and $500 \mathrm{cgs}$ ) were eliminated and two additional inoculum densities $\left(2.5 \times 10^{4}\right.$ and $\left.10^{5} \mathrm{cgs}\right)$ were added to determine at what level this antagonist would be effective. This repeated test yielded results similar to experiment 1, with the exception that Fo47 was effective at the higher inoculum densities of $2.5 \times 10^{4}$ and $10^{5} \mathrm{cgs}$.

Combined results of experiments 1 and 2 for each antagonist isolate were subjected to regression analysis to more clearly determine relationships among antagonist and pathogen densities for each isolate (Fig. 4, Table 4). For isolate CS-20, antagonist densities from 100 to $5,000 \mathrm{cgs}$ significantly reduced regression slopes $(b=0.096$ to 0.115 ) equally well over increasing pathogen densities relative to pathogen-infested controls $(b=0.338)$. There were no differences among antagonist densities in the ability to control disease. At a pathogen density of $1.25 \times 10^{4}$, disease incidence remained at about 20 to $25 \%$, regardless of the density of CS-20, compared with $>80 \%$ wilt incidence in the pathogen controls. Isolate CS-1 also reduced slopes of regression lines $(b=0.172$ to 0.218$)$, but was not as effective as CS-20, with disease incidences of 30 to $50 \%$ at a pathogen density of $1.25 \times 10^{4} \mathrm{cgs}$, compared with $72 \%$ wilt in pathogen controls. Isolate Fo47 did not significantly affect disease incidence as determined by regression slopes $(b=0.267$ to 0.294$)$ at antagonist densities from 100 to 5,000 cgs. However, antagonist densities of $2.5 \times 10^{4}$ and $10^{5} \mathrm{cgs}$ did significantly reduce disease incidence over all pathogen densities tested $(b=0.136$ and 0.098$)$.

In a follow-up test to determine the extent of effectiveness of the antagonists, isolates CS-1, CS-20, and a combination of both isolates added at a fixed antagonist density of $10^{3} \mathrm{cgs}$ were tested at pathogen densities up to $10^{5} \mathrm{cgs}$ (Fig. 5). Isolate CS-20, as well as the combination of isolates CS- 1 and CS-20, significantly reduced disease incidence at all pathogen densities tested, resulting in a disease incidence of 25 and $30 \%$, respectively, at a pathogen density of $10^{5} \mathrm{cgs}$, compared with $90 \%$ in the pathogen controls. Isolate CS-1 alone, however, although effective at pathogen densities up to $10^{4} \mathrm{cgs}$, was not effective in reducing disease incidence at pathogen densities greater than $10^{4} \mathrm{cgs}$.

TABLE 4. Slope values $(b)$ from linear regression analysis of the proportion of disease incidence versus $\log _{10}$-transformed pathogen density at varying antagonist densities for each of three biocontrol isolates, CS-1, CS-20, and Fo47

\begin{tabular}{lccc}
\hline & \multicolumn{3}{c}{ Antagonist isolate $^{\mathrm{b}}$} \\
\cline { 2 - 4 } Antagonist density $^{\mathrm{a}}$ & $\mathrm{CS}-1$ & $\mathrm{CS}-20$ & Fo47 \\
\hline 0 (no antagonist) & 0.310 & 0.338 & 0.343 \\
100 & $0.196^{*}$ & $0.107^{*}$ & 0.272 \\
500 & $0.168^{*}$ & $0.100^{*}$ & 0.275 \\
1,000 & $0.218^{*}$ & $0.115^{*}$ & 0.294 \\
5,000 & $0.172^{*}$ & $0.096^{*}$ & 0.267 \\
$2.5 \times 10^{4}$ & $\ldots$ & $\ldots$ & $0.136^{*}$ \\
$1.0 \times 10^{5}$ & $\ldots$ & $\ldots$ & $0.098^{*}$ \\
\hline
\end{tabular}

${ }^{a}$ Antagonist density as chlamydospores per $\mathrm{g}$ of soil (cgs). Each antagonist density was tested at each of five pathogen densities: 100, 500, 1,000, 2,500, and $12,500 \mathrm{cgs}$.

${ }^{\mathrm{b}}$ Values followed by an asterisk are significantly different $(P<0.05)$ from the pathogen control (0 antagonist level) for each biocontrol isolate according to Fisher's least significant difference (LSD) test. LSD values are $0.091,0.101$, and 0.151 for CS-1, CS-20, and Fo47, respectively. Graphical depiction of regression lines are shown in Figure 4.
Modeling dose-response relationships. Development of Fusarium wilt of tomato, as measured by wilt incidence, at defined pathogen inoculum densities was consistent across all three inoculum density experiments (repeated full scale test and smaller high pathogen density test). Dose-response models based on the LN, $\mathrm{NE}, \mathrm{HS}$, and LG functions were fit to the pathogen-only data (no biocontrol agents added) from all three experiments combined. All models fit reasonably well, but the LG model provided the overall best fit, followed closely by the HS model, as determined by MSE and chi-square tests (Fig. 6, Table 5). The NE and HS models fit best using raw (nontransformed) inoculum density data, whereas the LN and LG models required $\log _{10}$-transformed pathogen densities. The parameters calculated for these models indicated a pathogen $\mathrm{ED}_{50}$ of 3,273 and 1,779 cgs for the LG and HS models, respectively, and an asymptote of 0.826 for the HS model (LG asymptote assumed to be 1). The HS and LG pathogen models were then used in combination with the biocontrol components for all four model types and fit to the combined biocontrol data from all three experiments.

There were substantial differences among the three biocontrol isolates regarding which models provided the best fit, as well as the parameter values of those models (Table 6). Most model com-

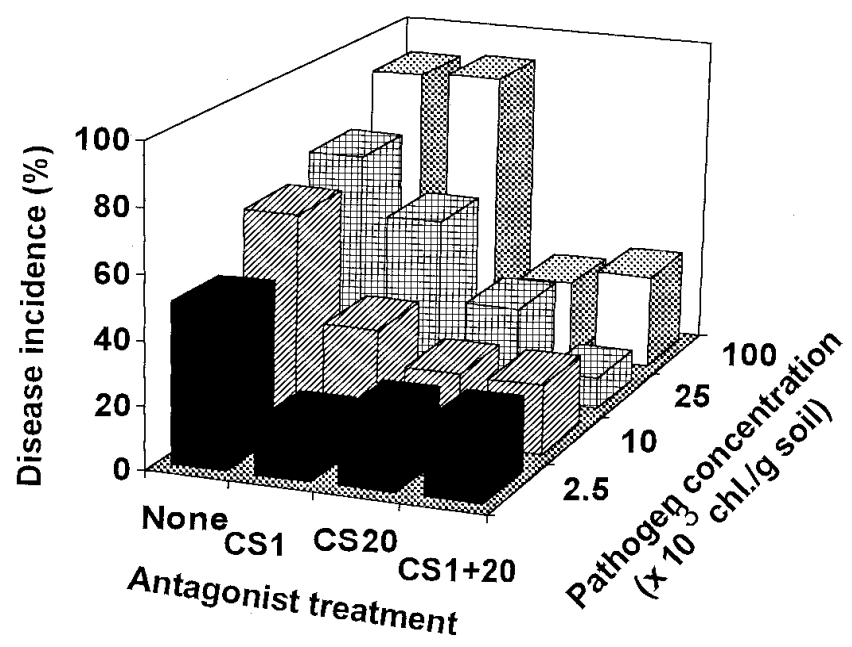

Fig. 5. Development of Fusarium wilt of tomato as affected by various biocontrol treatments and increasing pathogen densities. Biocontrol isolates were added at $1,000 \mathrm{CFU} / \mathrm{g}$ of soil prior to seeding. Isolate densities are expressed as chlamydospores per $g$ of soil. Data represent results of a single experiment.

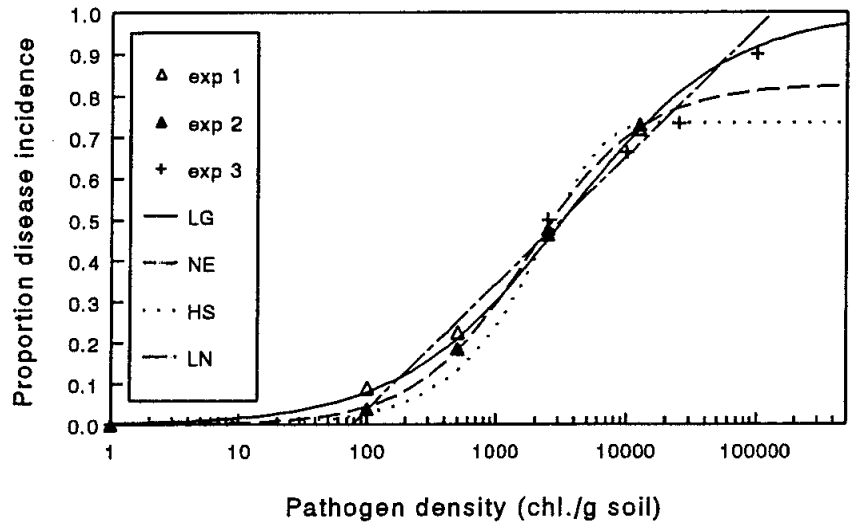

Fig. 6. Comparison of goodness-of-fit of four different epidemiological doseresponse models for the effect of increasing pathogen densities on development of Fusarium wilt of tomato. Models tested included the linear (LN), negative exponential (NE), hyperbolic saturation (HS), and logistic (LG) functions fit to data from three similar pathogen inoculum density experiments. Proportion of disease incidence represents percent disease incidence divided by 100 . Isolate densities are expressed as chlamydospores per $\mathrm{g}$ of soil. 
binations appeared to provide a reasonable fit (due mainly to the good fit of the pathogen component) based on MSE values. However, many models did not provide an adequate fit according to chi-square test values, due mainly to large deviations at either high or low densities. Both the NE and HS biocontrol component models provided comparable goodness-of-fit for isolates CS-1 and CS-20, whereas the LG biocontrol model provided the best fit for isolate Fo47. However, the HS pathogen model in combination with the NE and HS biocontrol components provided the best fit for isolate CS-1, whereas the LG/HS (pathogen/biocontrol) and LG/NE complete models were best for CS-20 and the LG/LG model was best for Fo47. Biocontrol parameter values for the best-fit models indicated a biocontrol $\mathrm{ED}_{50}$ of 2.6, 36.3, and $2.1 \times 10^{6} \mathrm{cgs}$ for CS-1, CS-20, and Fo47, respectively. The biocontrol asymptote parameter (defining biocontrol efficiency) for CS-1 and CS-20 was 0.229 and 0.539 , respectively, for the LG/HS model, whereas the rate parameter for the LG/LG model for Fo47 was 0.774. Models providing the best fit are shown plotted in relation to observed data for both increasing pathogen densities and antagonist densities in Figure 7 and graphically depict the differences among the three biocontrol isolates regarding inoculum density effects. Overall, biocontrol was not closely related to antagonist density for isolates CS-1 and CS-20, both providing comparable control at all antagonist densities (Fig. 7), whereas biocontrol by isolate Fo47 was closely related to antagonist density, with effective control only provided at very high antagonist densities $\left(>10^{4} \mathrm{cgs}\right)$. The ratio of the $\mathrm{ED}_{50}$ of the biocontrol to the $\mathrm{ED}_{50}$ of the pathogen, which is an indicator of relative inoculum efficiency of biocontrol agents, was 0.002, 0.011, and 641.6 for CS-1, CS-20, and Fo47, respectively.

\section{DISCUSSION}

In this study, three biocontrol isolates with apparently comparable effectiveness against Fusarium wilt diseases, based on previous inundative greenhouse assays (17), have been shown to differ dra- matically in regard to their mechanisms of action, dose-response relationships, and overall efficacy under varying conditions. These differences underscore the importance of such rigorous testing and evaluations to determine the conditions under which potential biocontrol agents will or will not be effective. Routine screening of biocontrol agents using high antagonist densities could not detect these differences, which may be critical for the success or failure of the biological control under varying environmental conditions. From the inoculum density experiments, we determined that CS-1 provided good control of Fusarium wilt at antagonist densities from 100 to $5,000 \mathrm{cgs}$ at moderate pathogen densities of 500 to $2,500 \mathrm{cgs}$, which represents the range of pathogen densities commonly observed in pathogen-infested fields (17). However, biological control by CS-1 broke down and was not effective at very high pathogen densities $\left(>10^{4} \mathrm{cgs}\right)$. CS-20, on the other hand, was effective at low antagonist densities (100 to $500 \mathrm{cgs}$ ) at all pathogen densities tested, up to $10^{5} \mathrm{cgs}$. For both of these isolates, efficacy was apparently not directly related to antagonist density, with low density providing comparable disease control to that of higher densities. From previous studies $(2,3,6,22)$, isolate Fo47 is known to be most effective when present at inoculum densities of 10 to 100 times that of the pathogen. Our studies corroborated these findings, showing that this isolate is effective only at high antagonist densities and at densities substantially greater than that of the pathogen.

Many of these observed differences in efficacy and dose-response relationships among the biocontrol isolates are probably related to differences in mechanisms of action and the efficacy of these mechanisms under varying conditions. Previous research with several isolates of nonpathogenic Fusarium spp. $(3,6,24)$ has established the importance of competition for glucose and other carbon compounds as mechanisms of action against pathogenic formae speciales of $F$. oxysporum. Indeed, previous studies had also determined that competition is the primary mechanism active in biological control by Fo47 (3,6,22). Our studies also indicated that competition is most likely the primary mode of action for this antagonist, based on re-

TABLE 5. Parameter values and goodness-of-fit for four pathogen dose-response models evaluated for development of Fusarium wilt of tomato by Fusarium oxysporum f. sp. lycopersici

\begin{tabular}{|c|c|c|c|c|c|c|c|}
\hline \multirow[b]{2}{*}{ Model $^{\mathrm{a}}$} & \multirow[b]{2}{*}{ Data format ${ }^{\mathrm{b}}$} & \multirow[b]{2}{*}{$\mathrm{MSE}^{\mathrm{c}}$} & \multirow[b]{2}{*}{$P^{\mathrm{d}}$} & \multicolumn{2}{|c|}{ Parameter $1^{\mathrm{e}}$} & \multicolumn{2}{|c|}{ Parameter $2^{\mathrm{e}}$} \\
\hline & & & & Symbol & Value & Symbol & Value \\
\hline Linear & $\log _{10}$ & 0.0352 & 0.77 & $a$ & 0.582 & $b$ & 0.309 \\
\hline Negative exponential & Raw & 0.0289 & 0.40 & $L$ & 0.736 & $k$ & 0.0004 \\
\hline Logistic & $\log _{10}$ & 0.0274 & 0.97 & $k_{1}$ & 1.621 & $p_{1}$ & 3.515 \\
\hline
\end{tabular}

${ }^{a}$ Models fit to combined pathogen density data (no biological control added) from three similar inoculum density experiments.

${ }^{\mathrm{b}}$ Data format represents whether raw pathogen density data or $\log _{10}$-transformed data was used to obtain best model fit.

c Mean square error (MSE) provides a measure of goodness-of-fit. The lower the MSE, the better the fit.

${ }^{\mathrm{d}}$ Probability of the chi-square test (model = observed). Higher values represent a better fit.

e Parameters and model equations are as described in Table 2.

TABLE 6. Parameter values and goodness-of-fit for four different biocontrol dose-response models evaluated for three different biocontrol isolates in combination with already established hyperbolic saturation and logistic pathogen models

\begin{tabular}{|c|c|c|c|c|c|c|c|c|c|c|c|c|}
\hline \multirow[b]{2}{*}{ Model $^{\mathrm{a}}$} & \multicolumn{4}{|c|}{ CS-1 } & \multicolumn{4}{|c|}{ CS-20 } & \multicolumn{4}{|c|}{ Fo47 } \\
\hline & $\mathrm{MSE}^{\mathrm{b}}$ & $P$ & $p_{1}$ & $p_{2}$ & MSE & $P$ & $p_{1}$ & $p_{2}$ & MSE & $P$ & $p_{1}$ & $p_{2}$ \\
\hline HS/LN & 0.0294 & 0.11 & 0.322 & 0.148 & 0.0522 & 0.001 & 0.622 & 0.097 & 0.0336 & 0.15 & -0.073 & 0.196 \\
\hline HS/LG & 0.0288 & 0.25 & 0.769 & 1.259 & 0.0462 & 0.001 & 1.318 & 0.637 & 0.0335 & 0.05 & 1.269 & 3.201 \\
\hline LG/LN & 0.0288 & 0.45 & 0.010 & 0.055 & 0.0369 & 0.05 & 0.012 & 0.117 & 0.0338 & 0.10 & -0.020 & 0.403 \\
\hline LG/NE & 0.0285 & 0.55 & 0.190 & 0.848 & 0.0363 & 0.12 & 0.415 & 0.647 & 0.0341 & 0.05 & 1.00 & 0.037 \\
\hline
\end{tabular}

a Model name consists of pathogen and biocontrol components used (e.g., LG/HS refers to the logistic pathogen component combined with the hyperbolic saturation biocontrol component). $\mathrm{HS}=$ hyperbolic saturation, $\mathrm{LG}=$ logistic, $\mathrm{LN}=$ linear, and $\mathrm{NE}=$ negative exponential. Model equations and parameters are listed in Table 2. Parameter values for the HS and LG pathogen components are listed in Table 5.

${ }^{\mathrm{b}} \mathrm{MSE}=$ mean square error from nonlinear regression analysis, lower values represent better model fits; $P=$ probability of the chi-square test $($ model $=$ observed), $p_{1}=$ parameter 1 , and $p_{2}=$ parameter 2 as defined in model equations in Table 2 .

c Parameter values followed by an asterisk represent the model showing the best fit to the observed data for each biocontrol isolate. 
sults from both the mechanism of action tests (chlamydospore germination and induced resistance) and the dose-response tests. Of the three isolates, only Fo47 was capable of significantly inhibiting saprophytic growth of the pathogen in soil. In addition, this isolate was only effective when antagonist densities were high and substantially greater than that of the pathogen, which is consistent with competition as a mode of action. High antagonist populations are generally required to effectively compete with the pathogen $(2,3)$. Although there also were indications of an induced resistance response in host plants due to Fo47, ISR was marginal and consistently weaker with Fo47 than with CS-20 and CS-1 in our tests, suggesting that ISR is not the primary mechanism of action.

The distinct differences in the extent and efficacy of ISR among the isolates suggests that there are varying degrees in either the ability of the isolates to induce resistance, the level of resistance induced, or in the type of resistance induced. Thus, the induction of resistance is apparently not an 'all-or-nothing' response, there are qualitative or quantitative differences in the resistance induced by different inducing agents. In this regard, CS-20 was the most efficient inducer of resistance, resulting in greater efficacy of disease reduction. CS-1 elicited either a weaker response or a different induced response that, although effective in reducing disease at low to moderate pathogen densities, was not effective at high pathogen levels. CS-1 is a different species $(F$. solani) than CS-20 (F. oxysporum) and there may be differences in the type of response, the extent of the response, or the pathway of the response induced by CS-1, resulting in lower efficacy at high pathogen densities.

Unfortunately, not much is known about the nature and physiology of the induction of resistance by Fusarium spp. It also is not yet known if the responses induced by Fusarium spp. are similar or different from those induced by other agents, such as plant growthpromoting rhizobacteria (13) or pathogen-related systemic acquired resistance (32). These types of induced resistance have been more extensively studied and are better characterized than is the resistance induced by Fusarium spp. ISR in these systems has been associated with the activation of multiple potential defense mechanisms including increased activity of chitinases, $\beta$-1,3-glucanases, peroxidases, and other pathogenesis-related (PR) proteins; accumulation of antimicrobial compounds such as phytoalexins; and formation of protective biopolymers such as lignin, callose, and hydroxyproline rich-glycoproteins $(13,32)$. In addition, a role for salicylic acid has been confirmed in some ISR reactions (32). ISR in these

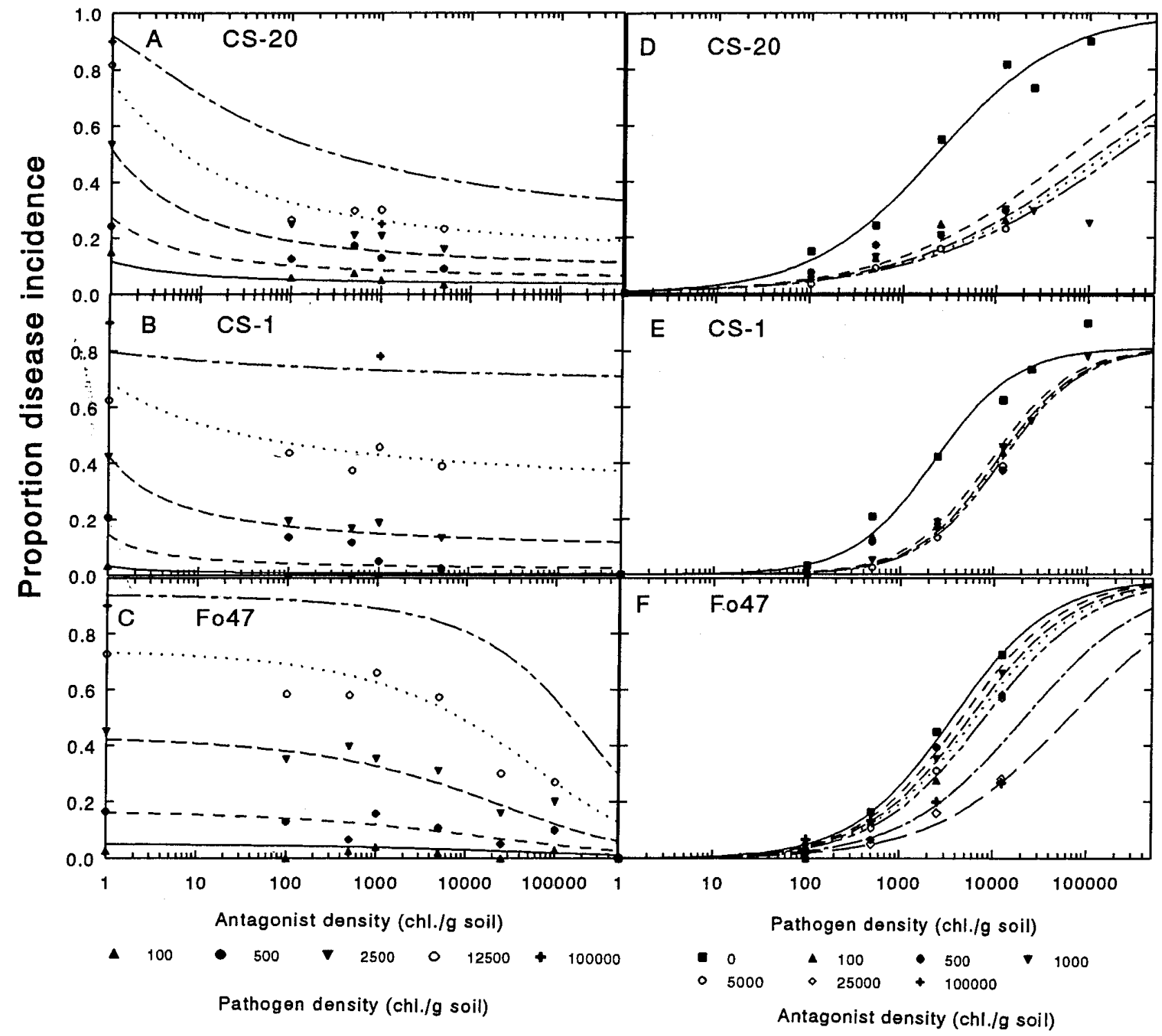

Fig. 7. Graphic depiction of disease incidence of Fusarium wilt of tomato predicted by the best-fit epidemiological pathogen-biocontrol models in relation to observed data as affected by $\mathbf{A}$ to $\mathbf{C}$, various pathogen densities at increasing antagonist densities, and $\mathbf{D}$ to $\mathbf{F}$, various antagonist densities at increasing pathogen densities for each of three biocontrol isolates: A and D, CS-20 using the logistic (LG)/hyperbolic saturation (HS) model; B and E, CS-1 using the HS/HS model; and C and F, Fo47 using the LG/LG model. Proportion of disease incidence represents percent disease incidence divided by 100. Isolate densities are expressed as chlamydospores per g of soil. Model equations, parameters, and goodness-of-fit estimates are shown in Tables 2, 5, and 6, respectively. 
systems has resulted in general resistance to multiple types and kinds of pathogens and diseases including soilborne and foliar forms of fungal, bacterial, and viral pathogens (13). With regard to induction by fusaria, Tamietti et al. (33) demonstrated increases in the activity of various glycosidase and oxidative enzymes in the roots, stems, and leaves of tomato plants whose roots were treated with biocontrol isolates of $F$. oxysporum. Interestingly, isolates of $F$. oxysporum that did not effectively reduce disease also did not increase the activity of these enzymes (33). However, it is not yet known what specific role, if any, these or other PR proteins play in the induced resistance of Fusarium wilt by $F$. oxysporum. It is also not yet known if the resistance produced by these Fusarium spp. is effective against other pathogens and diseases in addition to Fusarium wilt.

One of the primary benefits of ISR as a mechanism of action for these biocontrol isolates is that much lower inoculum levels were required than when competition was the mechanism of action. Both CS-1 and CS-20 were effective at inoculum levels of 100 to $500 \mathrm{cgs}$, which was two to three orders of magnitude lower than the inoculum dose required by Fo47. This could have very important implications on the application and implementation of these biocontrol isolates in the field. Much lower application levels could be used, and control would not be as adversely affected by fluctuations in populations of the biocontrol agent under varying environmental conditions.

The epidemiological dose-response models used in this study were useful for describing, clarifying, and characterizing the differences in the inoculum density relationships among the three biocontrol isolates. The fact that biological control was best described by a slightly different model for each of the three isolates emphasizes this point. The models clearly depicted the main attributes of the dose-response relationships for each of the isolates. For CS-20, the dose-response was characterized by effectiveness at low antagonist densities throughout all pathogen densities. For CS-1, it was characterized by effectiveness at low antagonist densities up to moderate pathogen densities, but breakdown of biological control at high pathogen densities. For Fo47, it was characterized by ineffectiveness at low to moderate densities and good effectiveness at high antagonist densities relative to pathogen density. The biggest difference, then, was apparently due to differences in mechanisms of action among the isolates. Biological control by CS-1 and CS-20 was not directly related to antagonist densities because of the nature of their mechanism of action, ISR. As long as there is adequate inoculum to colonize the roots, the density of CS-1 and CS-20 does not appear to be a major factor, whereas with isolate Fo47, high inoculum levels (particularly in relation to pathogen density) are crucial to enable its primary mechanism, competition, to be effective against the wilt pathogen in the soil and rhizosphere.

Overall, the models used to characterize biological control with these isolates fit the data fairly well. However, one must be careful not to put too much emphasis on models based on a limited number of data points. The model parameters emphasized the differences among the isolates, showing a low $\mathrm{ED}_{50}$ for CS-1 and CS-20 and a very high $\mathrm{ED}_{50}$ for Fo47. This was accentuated in the inoculum efficiency ratios (biocontrol $\mathrm{ED}_{50} /$ pathogen $\mathrm{ED}_{50}$ ), which was very low for CS-1 and CS-20 (0.002 and 0.011) and high for Fo47 (641.6). Comparison of these values with those of other biocontrol agents cited in other studies $(1,26)$ suggests that biological control by isolates CS-1 and CS-20 represent one of the most efficient (based on inoculum levels) systems studied, with efficiency values below those of several mycoparasite systems (0.16 to 5.0), other Fusarium biocontrol strains (9.9 to 63), and much lower than most bacterial antagonists and high density fungal antagonists such as Trichoderma and Gliocladium (150 to $\left.>10^{4}\right)$. The asymptote parameter $\left(I_{m}\right)$ from the LG/HS model for CS-1 and CS-20, representing the maximum amount of pathogen inoculum inactivated by the biocontrol agent, indicates the difference in efficacy between these two isolates, with CS-20 functionally inactivating over half $(0.539)$ the pathogen inoculum compared with a smaller proportion (0.229) for CS-1. Although these models were useful for differentiating and characterizing these isolates, models based on the unique attributes of induced resistance may need to be developed to more accurately assess these systems. The models used in this study were designed to be applied to inundative biocontrol situations, in which the most important criteria for characterizing disease and biological control are the inoculum densities of the pathogen and biocontrol agent. Clearly, in regard to isolates CS-1 and CS-20, density is not the primary determinant of biocontrol efficacy and, thus, some other types of models (not yet developed) that take other factors into consideration may be more applicable. With isolate CS-20, the models used tended to overestimate disease reduction due to biological control at low pathogen densities and underestimate biological control at high pathogen densities, because the fairly consistent level of biological control provided by this isolate throughout all pathogen densities could not be entirely accommodated by these models, which assume disease will increase dramatically with increasing inoculum density.

Overall, of the three isolates evaluated in this study, CS-20 is the most desirable biocontrol isolate for further study and development. It is effective at low antagonist densities, against all pathogen densities studied, including densities greater than $10^{5}$ propagules per $g$ of soil and over 100 times the density of the antagonist, and apparently is a good inducer of host defense responses. Currently, we are continuing to work to better understand the nature and development of biological control by CS-20 and other antagonists, as well as to develop and improve the level and effectiveness of control by these isolates, with the hope of developing a viable system of biological control for Fusarium wilt diseases.

\section{LITERATURE CITED}

1. Adams, P. B. 1990. The potential of mycoparasites for biological control of plant diseases. Annu. Rev. Phytopathol. 28:59-72.

2. Alabouvette, C., and Couteaudier, Y. 1992. Biological control of Fusarium wilts with nonpathogenic fusaria. Pages 415-426 in: Biological Control of Plant Diseases. E. C. Tjamos, G. C. Papavizas, and R. J. Cook, eds. Plenum Press, New York.

3. Alabouvette, C., Lemanceau, P., and Steinberg, C. 1993. Recent advances in the biological control of Fusarium wilts. Pestic. Sci. 37:365-373.

4. Alabouvette, C., Schippers, B., Lemanceau, P., and Bakker, P. A. H. M. 1998. Biological control of Fusarium wilts: Toward development of commercial products. Pages 15-36 in: Plant-Microbe Interactions and Biological Control. G. J. Boland and L. D. Kuykendall, eds. Marcel Dekker, New York.

5. Cook, R. J. 1993. Making greater use of introduced microorganisms for biological control of plant pathogens. Annu. Rev. Phytopathol. 31:53-80.

6. Couteaudier, Y. 1992. Competition for carbon in soil and rhizosphere; A mechanism involved in biological control of Fusarium wilts. Pages 99104 in: Biological Control of Plant Diseases: Progress and Challenges for the Future. E. C. Tjamos, G. C. Papavizas, and R. J. Cook, eds. Plenum Press, New York.

7. Datnoff, L. E., Nemec, S., and Pernezny, K. 1995. Biological control of Fusarium crown and root rot of tomato in Florida using Trichoderma harzianum and Glomus intraradices. Biol. Control 5:427-431.

8. Fravel, D. R., Adams, P. B., and Potts, W. B. 1992. Use of disease progress curves to study the effects of the biocontrol agent Sporidesmium sclerotivorum on lettuce drop. Biocontrol Sci. Technol. 2:341-348.

9. Fuchs, J.-G., Moënne-Loccoz, Y., and Défago, G. 1997. Nonpathogenic Fusarium oxysporum strain Fo47 induces resistance to Fusarium wilt in tomato. Plant Dis. 81:492-496.

10. Handelsman, J., and Stabb, K. 1996. Biocontrol of soilborne plant pathogens. Plant Cell 8:1855-1869.

11. Hebbar, K. P., Lewis, J. A., Poch, S. M., and Lumsden, R. D. 1996. Agricultural by-products as substrates for growth, conidiation, and chlamydospore formation by a potential mycoherbicide, Fusarium oxysporum strain EN4. Biocontrol Sci. Technol. 6:263-275.

12. Johnson, K. B. 1994. Dose-response relationships and inundative biological control. Phytopathology 84:780-784.

13. Kloepper, J. W., Zehnder, G. W., Tuzun, S., Murphy, J. F., Wei, G., Yao, C., and Raupach, G. 1996. Toward agricultural implementation of PGPRmediated induced systemic resistance against crop pests. Pages 165-174 
in: Advances in Biological Control of Plant Diseases. T. Wenhua, R. J. Cook, and A. Rovira, eds. China Agricultural University Press, Beijing, China.

14. Komada, H. 1975. Development of a selective medium for quantitative isolation of Fusarium oxysporum from natural soil. Rev. Plant Prot. Res. 8:115-125.

15. Kroon, B. A. M., Scheffer, R. J., and Elgersma, D. M. 1991. Induced resistance in tomato plants against Fusarium wilt invoked by Fusarium oxysporum f. sp. dianthi. Neth. J. Plant Pathol. 97:401-408.

16. Larkin, R. P., and Fravel, D. R. 1996. Ecological characteristics of biological control of Fusarium wilt of tomato using nonpathogenic Fusarium spp. (Abstr.) Phytopathology 86(suppl.):S9.

17. Larkin, R. P., and Fravel, D. R. 1998. Efficacy of various fungal and bacterial biocontrol organisms for control of Fusarium wilt of tomato. Plant Dis. 82:1022-1028.

18. Larkin, R. P., Hopkins, D. L., and Martin, F. N. 1993. Ecology of Fusarium oxysporum f. sp. niveum in soils suppressive and conducive to Fusarium wilt of watermelon. Phytopathology 83:1105-1116.

19. Larkin, R. P., Hopkins, D. L., and Martin, F. N. 1996. Suppression of Fusarium wilt of watermelon by nonpathogenic Fusarium oxysporum and other microorganisms recovered from a disease-suppressive soil. Phytopathology 86:812-819.

20. Larkin, R. P., Roberts, D. P., and Gracia-Garza, J. A. 1998. Biological control of fungal diseases. Pages 149-191 in: Fungicidal Activity: Chemical and Biological Approaches to Plant Protection. D. Hutson and J. Miyamoto, eds. John Wiley \& Sons, New York.

21. Leeman, M., van Pelt, J. A., Den Ouden, F. M., Heinsbrook, M., Bakker, P. A. H. M., and Schippers, B. 1995. Induction of systemic resistance by Pseudomonas fluorescens in radish cultivars differing in susceptibility to Fusarium wilt using a novel bioassay. Eur. J. Plant Pathol. 101:655-664.

22. Lemanceau, P. 1989. Role of competition for carbon and iron in mechanisms of soil suppressiveness to Fusarium wilts. Pages 385-395 in: Vascular Wilt Diseases of Plants. E. C. Tjamos and C. Beckman, eds. SpringerVerlag, New York.

23. Liu, L., Kloepper, J. W., and Tuzun, S. 1995. Induction of systemic resistance in cucumber against Fusarium wilt by plant growth-promoting rhizobacteria. Phytopathology 85:695-698.

24. Mandeel, Q., and Baker, R. 1991. Mechanisms involved in biological control of Fusarium wilt of cucumber with strains of nonpathogenic Fusarium oxysporum. Phytopathology 81:462-469.

25. Matta, A. 1989. Induced resistance to Fusarium wilt diseases. Pages $175-$ 195 in: Vascular Wilt Diseases of Plants. E. C. Tjamos and C. H. Beckman, eds. Springer-Verlag, New York.

26. Montesinos, E., and Bonaterra, A. 1996. Dose-response models in biological control of plant pathogens: An empirical verification. Phytopathology 86:464-472.

27. Ogawa, K., and Komada, H. 1986. Induction of systemic resistance against Fusarium wilt of sweet potato by non-pathogenic Fusarium oxysporum. Ann. Phytopathol. Soc. Jpn. 52:15-21.

28. Paulitz, T. C., Park, C. S., and Baker, R. 1987. Biological control of Fusarium wilt of cucumber with nonpathogenic isolates of Fusarium oxysporum. Can. J. Microbiol. 33:349-353.

29. Raaijmakers, J. M., Leeman, M., van Oorschot, M. M. P., van der Sluis, I., Schippers, B., and Bakker, P. A. H. M. 1995. Dose-response relationships in biological control of Fusarium wilt of radish by Pseudomonas spp. Phytopathology 85:1075-1081.

30. Schneider, R. W. 1984. Effects of nonpathogenic strains of Fusarium oxysporum on celery root infection by $F$. oxysporum $\mathrm{f}$. sp. apii and a novel use of the Lineweaver-Burk double reciprocal plot technique. Phytopathology 74:646-653.

31. Smith, K. P., Handelsman, J., and Goodman, R. M. 1997. Modeling doseresponse relationships in biological control: Partitioning host responses to the pathogen and biocontrol agent. Phytopathology 87:720-729.

32. Sticher, L., Mauch-Mani, B., and Metraux, J. P. 1997. Systemic acquired resistance. Annu. Rev. Phytopathol. 35:235-270.

33. Tamietti, G., Ferraris, L., Matta, A., and Abbattista Gentille, I. 1993. Physiological responses of tomato plants grown in Fusarium suppressive soil. J. Phytopathol. 138:66-76.

34. van Loon, L. C., Bakker, P. A. H. M., and Pieterse, C. M. J. 1998. Systemic resistance induced by rhizosphere bacteria. Annu. Rev. Phytopathol. 36:453-483.

35. van Peer, R., Niemann, G. J., and Schippers, B. 1991. Induced resistance and phytoalexin accumulation in biological control of Fusarium wilt of carnation by Pseudomonas sp. strain WCS417r. Phytopathology 81:728734. 